\title{
Editorial: Seção Especial
}

\section{Urban transitions and futures: a tale of governance, justice and security}

\author{
Alexandre B. Hedjazi, PhD - University of Geneva, Switzerland \\ Maria Dubraska Pineda, PhD - Naval Postgraduate School, USA
}

This special edition of urbe is the product of an ongoing initiative of the University of Geneva, UCLA and International City Environment Network (ICE ${ }^{\circ} \mathrm{NET}$ ). Within this framework two colloquia gathered colleagues from academia government and the private sector to reflect on the increasingly complex panorama of urban transformations across the planet. In 2007, a first group of academics and policymakers gathered in Geneva to address new sets of challenges that mid-size cities are increasingly being subject to. We then tracked significant challenges that emerging dynamics of change in respect to the environment (i.e. climate change) and energy (patterns of production and consumption) are imposing on urban areas. In addition by raising the singularity of midsize cities in terms of adaptive policy formulation and monitoring, we identified new barriers and enablers to mitigate the impacts of those challenges. The discussions aimed to set preliminary readings of new urban transformative trajectories.

\section{Urban futures \& transitions}

Since the 2007 colloquium undeniable patterns of change are depicting a new world. IPCC in its March 2014 report for policy makers raises the alarm unequivocally. "Many global risks of climate change are contracted in urban areas, heath stress, extreme precipitation, inland and coastal flooding, landslides, air pollution, drought, water scarcity pose risks in urban areas for people, assets, economies, and ecosystems" (IPCC, 2014, p. 18). The nexus of global dynamics of change and the trend of urbanization cannot be more alarming. Indeed, the United Nations confirmed in 2012 that 50\% of the world's population was already established in urban areas, reaching $70 \%$ by 2050 and that for most of humanity the future will be an Urban Future. However, within the context of drastic environmental change the quality of that Urban Future and its many dimensions are uncertain and difficult to decipher. Considering the scale and speed of global change across administrative and national boundaries, the wide scale impacts of change, what is clear is that the way we choose to act collectively will determine what our cities' future will be.

There is a widespread understanding that in face of century long development models, cities are today as many spaces of environmental degradation, production of unsustainable practices and new insecurities while perpetuating conditions of precarious living. Nevertheless, they also concentrate a plethora of means and tools and are in forefront of many global battles. Cities are therefore increasingly considered as many loci for virtuous actions. The complexity and variety of possible city-scenario is as unprecedented, 
pluri-dimensional, and dynamic as the risks they exponentially aggregate. While our modernist tools for policy and planning are limited and ill equipped to avert crisis and catastrophes, translation of science into policy and exchange of practices can draw new pathways towards sustainable change. As such, cities such as Geneva or Curitiba are among a constellation of actors actively leading the way towards sharing practices and knowledge transfer through various networks and alliances and continuous consultations.

In April 2013, the 7th ICLEI European Conference hosted by the city of Geneva provided another opportunity for exchanges between local governments; municipalities and other stakeholders involved in the transformative agendas of cities. The event was also the occasion for us to organize a second ICE ${ }^{\circ} \mathrm{NET}$ colloquium to connect policymakers with growing body of scientific research in Urban Transitions and Futures while. The discussions during ICLEI's plenary and breakout sessions validated the primacy of the thematic we discussed during our day of exchange on "Urban inflections". Built within the diversity of urban experiences and models we devoted discussions to exploring how the human, built and technological environments interact in the creation of the new spaces of life to complement the ongoing sharing of practices between actors.

Our primary assumption is that analysing the integration of the modernist efficient city and the postmodern multiplicity of city-spaces, should enable us to decipher the transition of the contemporary City to a new Urban Life-Space. Beyond fundamental role of exchange of practices and experiences between the decision makers with this edition of urbe we aim to reflect on some of theoretical and empirical underpinning of major dynamics of change that bridge the many dimensions of urban transitions by answering the following questions: 1)What is the "Good City" to aspire to? 2) How do we problematize, imagine, and create a new Urban Future? 3) How do we transition from the current Urban Dynamics to the more inclusive and sustainable Urban Life-Space?

In answering these questions we added new ideas and analytical frameworks to topics such as biodiversity, socio-political dimensions of Urban development, transportation and transit policies, impacts of climate change (e.g. heath islands), economic development vs. green growth, north-south cooperation and exchange, Urban citizenship and demographics or Urban security. So many notable authors have submitted their excellent and innovative articles that we had to pace the publications due to over subscription. And we plan to offer the urbe reader these valuable contributions in future editions. For this first special edition 5 very impressive articles were selected. They cover a wide scope from the theoretical to the applied. To our original vectors of analysis mentioned above, other voices were added and themes were proposed pointing out gaps and unveiling research options. This was illustrated by a suggestion by one the colloquium's participants to further the research on cross-sectoral challenges such as Climate Change and Urban Migration. Indeed, considering the scope of the phenomenon, planners and policy makers can not afford to dismiss the centrality of issues such as global environmental change impacts (climate in particular) on drivers of migration and displacement and the implications for urban development, security and integrated strategic urban policy for adaptation/mitigation/disaster risk resilience. Analysing the nexus of climate change and urban migration provides better planning and accommodate for increasing migrations while answering questions such as: how to avoid exacerbation of migrant vulnerabilities in cities? What are the operational and geopolitical implications of GEC driven migration at the city level?

Although, undoubtedly playing a role, the level of difficulty of pinpointing the correlation between climate change and the exponential growth of cities in developing countries illustrates the need for greater trans disciplinary scrutiny of emerging global urban dynamics. More generally, the massive process of urbanization is probably the most important socio-demographic phenomenon of our times, and it has manifold ecological, economic, political, social and cultural implications. It may become either a major calamity or a unique opportunity - depending on how it is handled. On the basis of these premises, five articles were selected for this special edition of urbe and peer reviewed to offer the highest scholarship in this domain, but also with the intention of stimulating further research and inspiration for this complex topic of transitions and transformation, that is happening in front of our eyes. 


\section{Methodology}

The articles are very diverse, methodologically, from semi-structured interviews for Toronto and Chicago, to a theoretical debate between major figures in planning theory and practice such as Henry Lefebvre and David Harvey. Featuring a diversity of methodological approaches in this selection shows how new vistas can be shed on established arguments, as well as make us realize how methodologically constrained we can be at times. Opening up to new forms of analysis and allowing new methodological approaches can offer us new research avenues and shed new light and ideas. Bridging disciplinary and methodological boundaries, analysing these transformation and answering to aforementioned questions we see a triads of complexity emerging in problematizing these transitions: 1) Governance/Justice/Security, 2) Sustainability/ Development/ Scale, 3) Resilience/ Risks/Vulnerability. These triads are inextricably bound and co-dependent in reinforcing feedback loops, and should not be studied in isolation, but in relationship to each other, for they are all co-dependent variables.

\section{Governance, justice, security}

While aiming a comprehensive picture of our changing world, the colloquium participants took stock of multiple crisis that have engulfed our urban planet spreading waves of anxiety and insecurity. These 'Black Swans' affected variably cities' trajectories towards a more prosperous sustainable future. Those cities that were ill prepared to withstand the shocks, have yielded to the pressures of change and are decaying, some have become feral or even criminal enclaves, while others have tried to overcome some of their vulnerabilities bouncing back with resilience and thriving with prosperity.

Indeed within the general context of rescaling, environmental, demographic and economic pressures, cities and local authorities are subject to increasing demand to fulfil the kind of obligations that states are ill equipped to deliver. In these conditions of uncertainty and insecurity, cities are currently designing and implementing urban programs under considerable debates about their impacts on the environment, and the capacity of current institutions to fund and manage extensive retrofitting projects or green infrastructure (PINCETL et al., 2012).

The promises of the "Modernist City", with its projections of wealth and prosperity through industrialization, have created unaccounted, risks and negative externalities reaching the 'limits to growth', exposing its marginal utility of that development model. Postmodern Urbanity, produced an infinite kaleidoscope of diversity, a cacophony of city identity-voices; an endless fragmentation into "adjectives-cities", leaving us disconnected in reconfigured simultaneous 'city-spaces', and lost among a multitude of discrete analytic and social silos of separation and atomized- schizophrenic identities. In the new Urban World of the 21 century we all aspire to "Good cities", people centered, capable of integrating the tangible and the more intangible aspects of prosperity, and in the process shedding off the inefficient, unsustainable forms and functionalities of the cities of the previous modern century.

Competing objectives make priorities difficult to negotiate among stakeholders and interests when development and security are expected while scale and speed of change keeps challenging current governance systems to establish accountability, implement regulations in simultaneous conflicting scenarios. Risks and Rewards are often incommensurate to the capabilities and exposures, privatizing gains and socializing liabilities, and in the processes circumventing justice and equity aspirations of the citizenry. The New Urban Space, where we aspire to have a fulfilling life, has to integrate these disparate fragments into a 'Politikon', an Urban Life-Space of social, economic and political meaning, a gestalt that is the Polis, that 'intains' in itself the Telos-objective and the means of achieving it. The real 'Politikon', demands a "Deep Transformation" of the economic, political and social practices and the construction of a new social reality of the City. Towards that goal and keeping in line with our original approach to complex themes, the selected articles for this first special edition of Urban Transformations center on issues of our triad on Security, Justice and Governance.

The first article is a theoretical essay by Orlando Santos that connects emerging urban alternatives and current dialectic between the dynamic of capital and appropriation of urban common spaces. Based on Henri Lefebvre and David Harvey's readings of production and appropriation of urban common spaces and 
the right to the city, the author revisits the contradictions and disputes among different agents that shape urban common spaces. In explaining the transformative nature of social movements, he further develops his arguments in favor of a just city as a requisite utopian basis under the premises of which a new collective demand or a new city project can emerge. As such a just city is a less alienated alternative urban life system promoting human emancipation.

To address conflicting voices and strategies of various agents, Santos arguments in favour of a "collective political platform" and coalition of like-minded with the aim of creating "new urban common spaces of political action". Such platform can only be based on recognition of heterotopic practices within the city. It is only under such premise that one can envisage creating "collective action towards re-appropriating processes" with the final goal of enabling the transition towards a more inclusive city based on principles of cosmopolitanism and social justice.

The second essay by Liette Gilbert connects further the transition to "greener urbanism" with the fundamental concept of social justice. Gilbert argument in favor of a just city brings to the forefront of the debate on sustainable Urban Futures the need for "redistributive purpose, social justice and social change". Drawing on scholarly work such as Harvey's and Fainstein's, the author provides elements of response to our first question and what is perceived as a good city. The author suggests that despite contradiction and conflicts between diversity, democracy and equity foundations of just city, these three elements constitute the very fabric of a just city where outcomes of policies ought to be redistributive.

Gilbert further explains "the ongoing difficulty to reconcile the social, economic and ecological perspectives within the reproduction of best practices" model. Taking stock of much celebrated examples of urban sustainability models in Stockholm, Hamburg, Copenhagen, San Francisco, Vancouver and Curitiba, Gilbert draws our attention to the silencing of "local knowledges', particular governance cultures, place specific intricacies' and historical specificities of places" on the premises of a dominant global discourse on urban sustainability.

In conclusion, Gilbert argues that "Urban transitions motivated by green neo-liberalism will only aggravate existing polarization, given that such transition generally occurs in the back of marginalized communities". Thus any urban transition model as a result of daily practices by the citizens ought to be inclusive of social justice to reinforce its revolutionary potentials while avoiding the sustainability performance trap.

Jan Berman in his essay; looks at how direct international city-to-city cooperation creates new institutional arrangements and social capital, that can change local policy and make substantive difference where state policy cannot. By presenting a case study of Indo- German city-to-city cooperation, the authors explores linkages among emerging trends in global climate governance and its conditions for failure and success.

Multi-level governance of climate change is increasingly focusing attention on cities, because cities are units of actions and can operationalize change much faster than national level institutions. This paper describes three initiatives with varying degrees of embededness into state legislation, and argues that "successful cooperation largely depends on the interplay between institutional forms and the development of social capital". "Whilst international climate change negotiations often end in deadlock and national governments adopt cautious climate policy approaches, many urban centres across the world are taking the lead' assert the authors. They find that more and more cities from the 'Global North', as well as urban centres from the 'Emerging South' are taking the initiatives to individually reduce their local carbon footprints.

Another trend is emerging, according to the authors that show an "expanding urban North-South cooperation in the area of low carbon development. Such cooperation, they observe, "takes various forms, such as city twinning, transnational municipal networks and trans-local development cooperation a key target of these initiatives is to develop joint projects and exchange knowledge in order to foster low-carbon development pathways". In reading the paper it is important to reflect on what can be observed from the emergence of urban North-South cooperation $d$ how that emerging trend can help objectives and bridge development divides and climate impacts.

The question of multilevel governance and the rescaling of decision-making process and policy formulation is at the heart of our forth article. Through their essay Tremlay-Racicot and Mercier point to political 
dynamics in Toronto and Chicago showing "that the capacity of metropolitan institutions to adopt and implement plans that integrate transportation with land use depends essentially on the leadership of the province or the state government". The article engage the reader in a reflection on how in a multilevel decision-making, the structure of authority can get fragmented and ineffective in creating a coherent metropolitan vision. The authors suggest "In the absence of leadership at the provincial or state level, the presence of a policy entrepreneur or a strong civic capacity at the regional level can be a key factor in the adoption and implementation of innovative reforms". Through the case of Toronto and Chicago the contribution of this article to the existing literature on urban transitions situates the debate on the difficulty of policy formulation within the transition to a new stage of rescaling of governance depicted by greater number of actors with distinct priorities involved in decision-making process.

The final article entitled addresses the question of security as an intrinsic element of urban transitions. In his article Nicholas Kasang positions the debate on urban transitions at the crossroad of emerging insecurities. With increased urbanization violence and homicides in many parts of the world have reached unfathomable levels and Latin America is host to the most violent cities in the world. "Caracas is particular, as its exorbitant homicide rate cannot be attributed to the illicit drug trade-cartel wars that consume Mexico, nor is it represented by the civil conflict-gang violence that afflicts Central America....nor inequality - consistently cited as the primary catalyst for the emergence of everyday reactionary violence - is not overtly characteristic of the contemporary situation (in Venezuela)."

Kasang proposes the development of 'socio-spatial interventions' along the lines of six prevention criteria based on evidence that such interventions suggest "significant capacity to prevent the occurrence of violence in areas that are either totally or partially excluded from economic development and larger society" (DÍAZ, MELLER, 2012, p. 23). The author offers a comprehensive literature review and uses data analyses in the development of a spatial proposal for Caracas as a last resort since the type of insecurity experienced in Caracas "has largely been attributed to the exacerbation of determined social factors, perpetuating violence as "an end in itself or a [mechanism] to injure/eliminate another person in order to resolve an interpersonal conflict" (SANJUÁN 2002, p. 95).

In conclusion this last article is a valuable addition to the debate on security dimension of urban transitions as it has the potential applicability to other urban settings where such violence is occurring. It shows how special interventions can be an added tool in changing the patterns of violence augmenting the technical violence preventions mechanisms that traditional police and security agencies implement.

Together with the relentless urbe team, we are devoted to exploring the ever changing dynamics of urban transformation, what drives it and how the human, built and technological environments interact in the creation of the new space of life of the 21 century. We invite you to read and comment on this special selection and encourage you to address further these complex topics and the many open questions in respect to the new urban world we are transiting to. These articles give us some glimpses.

\section{References}

PINCETL, S. et al. Urban tree planting function or fashion? Los Angeles and urban tree planting campaigns. GeoJournal, v. 78, n. 3, p. 475-493, June 2013.

INTERGOVERnMENTAL PANEL ON CLIMATE CHANGE (IPCC). Press release - Summary for Policy Makers. 2014. Available at: <http://ipcc-wg2.gov/AR5/images/uploads/IPCC_WG2AR5_SPM_Approved.pdf>. Accessed in: Mar. $2014 .$.

DÍAZ, F. J.; MELLER, P. (Ed.). Violencia y Cohesión Social en América Latina. Santiago: Uqbar Editores, 2012.

SANJUÁN, A. M. Democracy, Citizenship, and Violence in Venezuela. In: ROTKER, S.; GOLDMAN, K. (Ed.). Citizens of Fear: Urban Violence in Latin America. New Brunswick, NJ: Rutgers University Press, 2002. p. 87-101. 